\title{
CONCEPTUALISATION OF ECONOMIC CRISIS IN DISCOURSE: FROM THE GREAT DEPRESSION TO THE GREAT RECESSION
}

\author{
Natalya Oliynyk \\ V. N. Karazin Kharkiv National University, Kharkiv, Ukraine \\ dilovamova@karazin.ua \\ Iryna Shevchenko \\ V. N. Karazin Kharkiv National University, Kharkiv, Ukraine \\ dilovamova@karazin.ua
}

\begin{abstract}
The article considers conceptual representation of ECONOMIC CRISIS in the economic mass-media discourse of the two historical periods: 1929-1933 and 2007-2010 to reveal its synchronic and diachronic distinctions and dichotomies. More specifically, it is aimed to study linguistic means representing the concept in the $20^{\text {th }}$ century and determine their diachronic variations. Applying cognitive linguistic instruments, such as component analysis and conceptual metaphor theory, it has been determined that conceptual content, structure and metaphorical representation of ECONOMIC CRISIS are subject to historical variations. Terminologically motivated name of the concept "economic crisis" provides historical stability of its content and structure formed by historical constants DECLINE, UNSTABLE SITUATION, TURNING POINT on the one hand, and affects its historical change: extension with new constituents - variables DISORDER, LANDMARK, ACCIDENT, on the other. Propositional schemas of the concept, mainly those of action and identification, form the cognitive structure of ECONOMIC CRISIS and vary diachronically in the degree of prominence. The dominant conceptual metaphors of ECONOMIC CRISIS of a target domain CRISIS is MOVEMENT DOWN and CRISIS is A STATE OF EMERGENCY are stable through history while their further division into clusters of metaphors varies both in the set of source domains and in their frequency in discourse.
\end{abstract}

Keywords: conceptual metaphor; concept; economic crisis; diachronic variation; terminological motivation.

\section{Introduction}

The concept of "crisis" has always provoked the interest of scholars with its ambivalent nature and semantic ambiguity. Since 1929 "crisis" has become an expression of a new sense of time which both indicated and intensified the beginning of an epoch of crises: its semantic range was extended with a new meaning "stock-market crisis" referring to the Wall Street Crash of the 1930s generally known as the Great Depression. Further increasingly severe economic emergencies, as well as the development of the science of economics, urged to life the new term "economic crisis" which has become the object of analysis in social, political, and economic studies. In linguistics, this term is ascribed to an economic or business discourse.

The recent data of social and economic research link current economic events to those of the 1930s. They give more attention to the Great Depression of the 1930s as the longest and most severe economic crisis of modern times experienced by the industrialised Western world (Pells, 1998). The necessity of a linguistic study of ECONOMIC CRISIS is stipulated, on the one hand, by its unprecedented social impact and, on the other, by the historic perspective taken in our research (the discourses of the Great Depression $v s$ that of the present global crisis also called the Great Recession) revealed by modern methods of cognitive linguistics.

We argue that the concept ECONOMIC CRISIS undergoes historical transformations with the development of English media discourse. In this paper, we aim to establish the role and place of the concept ECONOMIC CRISIS in conceptual spheres of the English-speaking societies and their historic shift in 1929-1933 and 2007-2010 by determining language means and cognitive devices used for representing ECONOMIC CRISIS in the English media discourse. Our objective is to define the content and structure of the concept ECONOMIC CRISIS expressed by language means and their diachronic variation in the economic media discourses of the two periods.

The theoretical background of this work in part reflects not only the varied academic backgrounds of the scholars, but also the evolutionary development of cognitive linguistics in general and its sub-disciplines of cognitive semantics and historical cognitive linguistics in particular. The study is based on the cognitive approach to the analysis of linguistic units and contributes to the development of historical cognitive linguistics (Shevchenko, 2015; Winters, 2010). Diachronic approach leads to work on the principle that "being a part of human social and cultural practice cognition is of historic nature" (Shevchenko, 2015, p. 64). Culture is a changing system "by which a society adapts to its environment. It is the system through which a society adapts to its environment. Given a changing environment, in the long run it is likely to change." (Inglehart, 1990, p. 55) 
In this regard, linguistic research requires diachronic approach as both language and culture can manifest their dynamics and variability through time only in socio-historical facts.

\section{Method}

In this paper, we first describe semantic properties of the name of the concept - word combination "economic crisis". Then we model the structure of the concept ECONOMIC CRISIS viewed as a linguocultural unit of knowledge with a syncretic notional-evaluative and image-evaluative components (Oliynyk, 2015 p. 39-43).

Modern cognitive linguistics rests upon two guiding principles that (1) language is an integral part of cognition (Lakoff, 1990, p. 40) and (2) it is symbolic in nature (Langacker, 1987, p. 11). It allows the scholars to put meaning in the centre of any study under this approach. As G. Fauconnier puts it: "Cognitive linguistics goes beyond the visible structure of language and investigates the considerably more complex backstage operations of cognition that create grammar, conceptualization, discourse, and thought itself." (2006, p. 10).

At the first stage of this research, we singled out semantic properties of the concept from all the meanings of its name provided in dictionary definitions. Then following Langacker (1987) who points out that "there should not be any difference in kind between conceptual structure and semantic structure; there is only a terminological distinction, the former being general the latter specifically linguistic" (p. 98), we applied a cognitive operation of categorisation to those semantic properties in order to see how the conceptual content is construed and whether it changed through time. Here, we rely on a linguistic manifestation of cognitive economy, one of the principles of category formation proposed by Rosch (1978, p. 4). To reveal the relation between semantic and conceptual properties we built up a cognitive model using the "semantics of lingual networks" (SLN) methodology developed by S. Zhabotynska (2010).

To establish the range of ECONOMIC CRISIS cognitive metaphor we used the ideas and findings of metaphor theory (Lakoff \& Johnson, 1980) stating that it is a system of metaphor that structures our everyday conceptual system and transforms our bodily and interactional experience to abstract conceptual structures. Conceptual metaphor is understood as a tightly structured mapping (in the mathematical sense) from a source domain to a target domain with a set of ontological correspondences that characterise a mapping with metaphorical expressions being "tied to metaphorical concepts in a systematic way" (p. 7).

In this analysis, we rely on 5164 discourse fragments naming ECONOMIC CRISIS from The Economist (ECNM), The Financial Times (FT), The New York Times (NYT) (1929-1933 and 2007-2010).

\section{Results and Discussion}

The structure of the concept is much more complicated and more varied than the lexical meaning of words. ECONOMIC CRISIS is conceptualised in discourse by literal linguistic means (words and wordcombinations) and by figurative ones (cognitive metaphors). Its content is stored in the verbal form and manifested by its name - the term "economic crisis" defined as "a situation in which the economy of a country experiences a sudden downturn brought on by a financial crisis. An economy facing an economic crisis will most likely experience a falling GDP, a drying up of liquidity and rising/falling prices due to inflation/deflation" (Economic crisis, 2016). According to this Business dictionary definition the name of the concept is terminological by its nature and as such, possesses term properties - definition, meaning correspondence, strictness of the term; serves as "a designation of a specific concept of science" (Leitchik \& Shelov, 2003, p. 90). The content of ECONOMIC CRISIS is disclosed by the meanings of the key lexeme "crisis", a modifying adjective "economic" and the term "economic crisis" itself and can be explained as a category of understanding based on cognitive models.

According to dictionaries, "crisis" is a polysemous word with 12 lexical meanings which we organised into the conceptual model of polysemy by S. Zhabotynska's methodology of SLN with the help of the limited set of propositional schemas (classification, causation, likeness) to structure semantic properties and distribute them between the conceptual domains they refer to (Oliynyk, 2015, p. 78). They are profiled within six overlapping domains: MEDICINE with two subdomains DISEASE (1. turning point in the course of a disease; 1.1. malfunction; 1.2. a paroxysmal attack of pain, distress, or disordered function) and PSCHYOLOGICAL STATE (2. a stage in a sequence of events at which the trend of all future events, especially for better or for worse, is determined; 2.1. an emotionally significant event or radical change of status in a person's life, 2.2. a state of anxiety or discomfort caused by not being sure about what type of person you are; 2.3. a time when a difficult or important decision must be made); ECONOMY (3. an unstable period, esp. one of extreme trouble or danger in politics, economics, etc; 3.1. shortage, deficit of sth; 3.2. stock market crisis); POLITICS (3.); LITERATURE (4. the point in a play or story at which hostile 
elements are most tensely opposed to each other); ASTRONOMY (5. a conjunction of the planets which determines the issue of a disease or critical point in the course of events).

Semantic domains determine "a database" of the nominative space of the concept and demonstrate its hierarchical nexus: the integral semantic properties "unstable economic situation", "economic decline", "landmark" ("depression of the 1930s") and the differential semantic properties "malfunction, "situation of extreme danger", "difficulty", "anxiety", "disorder", "shortage of financial resources", "culminating point of action", "accident", "a falling GDP", "rising/falling prices", "inflation/deflation", "long-term".

In the centre of the conceptual model representing a semantic space of the concept, there is an internal form "turning point" involved in generating new meanings of the name and semantic content of ECONOMIC CRISIS.

The results of our interpretation are presented in the table below where $\mathrm{n}_{1}, \mathrm{n}_{2}$ represent data for the two historical periods and $\mathrm{p}_{1}, \mathrm{p}_{2}$ represent their percentage rate from the total number of nominations $(100 \%)$.

Conceptual content of ECONOMIC CRISIS in 1929 - 1933 and 2007 - 2010

Table 1

\begin{tabular}{|l|c|c|c|c|}
\hline \multicolumn{1}{|c|}{ Conceptual domains } & $\begin{array}{c}1929-1933 \\
\left(\mathrm{n}_{1}\right)\end{array}$ & $\begin{array}{c}\text { frequency }(\%) \\
\left(\mathrm{p}_{1}\right)\end{array}$ & $\begin{array}{c}2007-2010 \\
\left(\mathrm{n}_{2}\right)\end{array}$ & $\begin{array}{c}\text { frequency }(\%) \\
\left(\mathrm{p}_{2}\right)\end{array}$ \\
\hline DECLINE & 423 & 56,58 & 457 & 38,33 \\
\hline subdomain CHANGE & 403 & 53,96 & 430 & 36,08 \\
\hline subdomain CULMINATION & 20 & 2,62 & 27 & 2,25 \\
\hline UNSTABLE SITUATION & 310 & 41,49 & 674 & 56,62 \\
\hline subdomain ANXIETY & 125 & 16,72 & 151 & 12,66 \\
\hline subdomain MALFUNCTION & 65 & 8,75 & 159 & 13,35 \\
\hline subdomain DIFFICULTY & 58 & 7,76 & 24 & 1,99 \\
\hline subdomain SHORTAGE & 39 & 5,16 & 175 & 14,71 \\
\hline subdomain DANGER & 23 & 3,10 & 153 & 12,827 \\
\hline subdomain DISORDER & - & - & 13 & 1,07 \\
\hline TURNING POINT & 14 & 1,93 & 60 & 5,05 \\
\hline subdomain ACCIDENT & - & - & 35 & 2,95 \\
\hline subdomain LANDMARK & - & - & 25 & 2,1 \\
\hline Sum-total & 748 & $100 \%$ & 1191 & $100 \%$ \\
\hline
\end{tabular}

Table 1 shows that the content of ECONOMIC CRISIS is arranged with three conceptual domains - the historical constants DECLINE, UNSTABLE SITUATION, TURNING POINT and their subdomains embodied with distinct meanings of particular words used to express ECONOMIC CRISIS in the discourse of the two periods. Terminological nature of the name of the concept provides its structural stability by means of causative and qualitative relations motivated by negatively evaluated semantic properties "change" and "culmination".

The notional structure of the concept and links between its constituents were exposed with the help of SLN research instrument. The following examples (Oliynyk, 2015), illustrate the links lying in the basis of the concept structure: the causative schema "CR-causer makes FT-factitive", as S. Zhabotynska (2010) argues, models a transitive act that results in creating a new thing (FT) by the agent (or instrument) that becomes the causer (CR) (p. 82). So, "CR-UNSTABLE SITUATION causes FT- consequences" where the consequences are: MALFUNCTION (bubble, collapse, crash, disaster, distress, failure); SHORTAGE (contraction, debt, deficit, scarce); ANXIETY (concern, depression, fear, gloom, panic, strain, stress, trouble). For example:

The situation strikingly indicates the inherent instability of the system, $<\ldots>$ which has been the major cause of the nation-wide crisis (FT, 26 Oct 1929).

Another instance is the causative schema "CR-DISORDER makes FT-consequences" where the consequences are DECLINE, MALFUNCTION, SHORTAGE and ANXIETY. These links were not found in the 1930s due to the absence of the concept DISORDER. They only appear in the discourse of the current global crisis. For example:

Global markets saw record falls in 2008 as the financial turmoil and economic slowdown ended the stock market boom (NYT, 8 Oct 2008).

In the same way, it was determined that the concept TURNING POINT acquires new syntactic and semantic properties: ID-TURNING POINT is CH-characterizer" where characterizer is LANDMARK. The 
latter is verbalised in discourse by "once-in-a-century type of event, "Great Recession" (as a play on the term "Great Depression"). For example:

It has become known as the "Great Recession", the year when the global economy suffered its deepest slump since World War II (ECNM, 7 Aug 2008).

The quantitative analysis results (the frequency rate of particular concepts or conceptual domains) gave grounds to determine the degree of their prominence and state that the conceptual content of ECONOMIC CRISIS demonstrated variability in terms of its composition: the concepts DISORDER, LANDMARK and ACCIDENT manifested themselves during the period of current global crisis of the 2000s. Moreover, there has been a shift of domains DECLINE and UNSTABLE SITUATION: the former dominated in the period of the 1930s (56\%) and then its prominence degree fell by 18\% giving place to UNSTABLE SITUATION in the 2000s. So, the conceptual content underwent historical transformations showing a tendency for extending its semantic space through time with three new concepts.

Our next step of analysis revealed the cognitive metaphors used to describe ECONOMIC CRISIS. The sampling included 2684 metaphorical expressions guided by certain scenarios (mappings) revealing the metaphoric nature of ECONOMIC CRISIS. We presented these scenarios with mnemonic names in the form of the model TARGET-DOMAIN IS SOURCE-DOMAIN where each domain refers to a certain abstract conceptual structure - a concept (or a cluster of related concepts) following Z. Kovecses's (2009) definition of metaphor "as understanding one conceptual domain in terms of another conceptual domain" (p. 4).

The table below shows empirical findings on a set of conceptual metaphor mappings of ECONOMIC CRISIS (range of metaphors) in two time periods of the 1930s and 2000s.

Table 2

Metaphorical conceptualization of ECONOMIC CRISIS in 1929 - 1933 and 2007 - 2010

\begin{tabular}{|l|c|c|c|c|}
\hline \multicolumn{1}{|c|}{ Source domains } & $\begin{array}{c}1929-1933 \\
\left(\mathrm{n}_{1}\right)\end{array}$ & $\begin{array}{c}\text { frequency }(\%) \\
\left(\mathrm{p}_{1}\right)\end{array}$ & $\begin{array}{c}2007-2010 \\
\left(\mathrm{n}_{2}\right)\end{array}$ & $\begin{array}{c}\text { frequency }(\%) \\
\left(\mathrm{p}_{2}\right)\end{array}$ \\
\hline MOVEMENT & 645 & $\mathbf{6 4 , 2 4}$ & 733 & $\mathbf{4 3 , 6 3}$ \\
\hline DISEASE & 117 & 11,65 & 172 & 10,24 \\
\hline NATURAL DISASTER & 54 & 5,38 & 72 & 4,29 \\
\hline WAR & 46 & 4,58 & 110 & 6,55 \\
\hline CONTAINER & 29 & 2,89 & 72 & 4,29 \\
\hline MACHINES and TOOLS & 26 & 2,59 & 26 & 1,55 \\
\hline MAN & 25 & 2,49 & 34 & 2,02 \\
\hline RELIGION & 11 & 1,1 & 43 & 2,56 \\
\hline MAN-MADE DISASTER & 10 & 1,0 & 329 & $\mathbf{1 9 , 5 8}$ \\
\hline BUILDING & 10 & 1,0 & 15 & 0,89 \\
\hline STORY & 9 & 0,9 & - & - \\
\hline CELESTIAL BODY & 9 & 0,9 & - & - \\
\hline ANIMAL & 7 & 0,7 & 6 & 0,36 \\
\hline PLANT & 6 & 0,6 & 18 & 1,07 \\
\hline PLAY/MOVIE & - & - & 38 & 2,26 \\
\hline COOKING and FOOD & - & - & 12 & 0,71 \\
\hline Sum-total & 1004 & $100 \%$ & 1680 & $100 \%$ \\
\hline
\end{tabular}

According to table 2, the data received ECONOMIC CRISIS is metaphorically conceptualised in terms of a wide range of domains with orientation, ontological and structural metaphors. The former type of metaphors dominates in both periods and represented by the conceptual metaphor ECONOMIC CRISIS IS MOVEMENT with the highest metaphorical potential $-64 \%$ and $43 \%$ in the 1930 s and the $2000 \mathrm{~s}$ respectively.

In the range of source domains of ECONOMIC CRISIS, there are historical constants MOVEMENT, DISEASE, NATURAL DISASTER, WAR, CONTAINER, MACHINES and TOOLS, MAN, RELIGION, MAN-MADE DISASTER, BUILDING, ANIMAL, PLANT which vary historically only in terms of their occurrence in discourses of the two periods. The most significant change refers to the domain MAN-MADE DISASTER whose rate increased by $18 \%$ in the $2000 \mathrm{~s}$. We assume that the increasing role of this particular domain is mainly explained by negative effects of technological developments causing nuclear accidents, explosions and other environment related problems. Such metaphors highlight first of all negative aspect of ECONOMIC CRISIS as an extremely dangerous, destructive and disastrous event: e.g., a credit meltdown 
affecting the entire global financial system (FT, 18 Dec 2008); ... what would happen to the economy in the financial nuclear winter that would follow (ECNM, 19 March 2008).

This and other source domains can be further conceptualised by another source. Thus, the conceptual domain MOVEMENT is specified by the following cluster of metaphoric concepts: MOVEMENT DOWN (e.g., loans moved downward (FT, 7 Jan 1931); severe declines occurring in the prices of wheat (ECNM, 16 Nov 1929); MOVEMENT UP (e.g., increased speculative buying (FT, 12 Feb 1932); MOVEMENT BACKWARD (e.g., the Wall Street shake-out (ECNM, 26 Oct 1929); a massive rebound on Wall Street (FT, 17 Sep 2008).

It should be noted that unlike general assumptions "UP IS GOOD" and "DOWN IS BAD" the conceptual metaphor ECONOMIC CRISIS IS MOVEMENT UP realises negative scenario by a wide variety of expressions, e.g., prices skyrocketed (FT, 18 March 1932); the surges this year in oil and food prices (NYT, 1 Aug 2008); ... the cost of borrowing soared for many companies (NYT, 12 Sep 2009).

\section{Conclusion}

In sum, this empirical analysis proved our assumption that the conceptual content and metaphoric representation of ECONOMIC CRISIS in two historical periods is subject to variation. ECONOMIC CRISIS is a linguo-cultural concept with syncretic notional-evaluative and image-evaluative components.

Propositional schemas of the concept reveal inner conceptual relations determined by its name - a terminological word-combination economic crisis. Historical constants - concepts DECLINE, UNSTABLE SITUATION, TURNING POINT and variables DISORDER, LANDMARK, ACCIDENT form the cognitive structure of ECONOMIC CRISIS. The set of these concepts is stable through history but varies diachronically in the degree of prominence.

In both historical periods, the basic cognitive metaphor model (a historical constant) is ECONOMIC CRISIS is MOVEMENT DOWN. Historically, the range of source domains and their metaphoric potential tend to grow thus revealing historical variations of ECONOMIC CRISIS.

On the whole, the theoretical or practical significance of the results obtained is determined by their contribution to cognitive linguistics, cognitive semantics and the theory of metaphor. Our findings will be of use to model the dynamics of concepts through history: their linguistic embodiment, structure (concept schemas), range and scope of conceptual metaphors. The outcomes of our study will also stimulate the development of a new research paradigm in linguistics - historical concept studies and open up perspectives to further investigation of concepts' evolution on the material of Ukrainian and other languages.

\section{References:}

Economic crisis. (2016). BusinessDictionary.com. WebFinance Inc. Retrieved from http://www.businessdictionary.com/definition/ec onomic-crisis.html

Fauconnier, G. (2006). Cognitive Linguistics. Encyclopedia of Cognitive Science (pp. 1 14). https://doi.org/10.1002/0470018860.s00214 Inglehart, R. (1990). Culture Shift in Advanced Industrial Society. Princeton: Princeton University Press.

Lakoff, G. (1990). The Invariance Hypothesis: Is Abstract Reason Based on Image-Schemas? Cognitive Linguistics, 1, 39-74. https://doi.org/10.1515/cogl.1990.1.1.39

Lakoff, G., \& Johnson, M. (1980). Metaphors we live by. Chicago: University of Chicago Press

Langacker, R.W. (1987). Foundations of Cognitive Grammar, 1: Theoretical Prerequisites. Stanford, California: Stanford University Press.

Leitchik, V.M. \& Shelov, S.D. (2003). Some basic concepts of terminology: Traditions and innovations. Terminology Science \& Research, 14, 86-101.

Oliynyk, N.A. (2015). Koncept EKONOMICHESKIJ KRIZIS v anglojazychnom ekonomicheskom diskurse 1930-h i 2000-h godov [The concept ECONOMIC CRISIS in the English economic discourse of the 1930s and 2000s]. Harkov, Ukraine: V. N. Karazin Kharkiv National University. Retrieved from http://dspace.univer.kharkov.ua/bitstream/123456789/10992/3/ dis_Oliynyk.pdf

Pells, R. (1998). Radical visions and American dreams: culture and social thought in the Depression years. Urbana \& Chicago: University of Illinois Press

Rosch, E. (1978). Principles of categorization. In E. Rosch, B. L. Lloyd (Eds), Cognition and categorization (1-25): Hillsdale, NJ: Lawrence Erlbaum. Retrieved from http://commonweb.unifr.ch/artsdean/pub/gestens/f/as/files/4610/9778_083247.pdf

Shevchenko, I.S. (2015). Transformations of expressives through history in cognitive-communicative perspective. V.N. Karazin Univ. messenger, 1155, 64-68. Retrieved from: http://dspace.univer.kharkov.ua/handle/123456789/11086

Winters, M.E. (2010). Introduction: On the emergence of diachronic cognitive linguistics. In Winters, M.E, Tissari, H \& Allan, K (Eds), Historical Cognitive Linguistics (pp.3-28). Berlin: De Gruyter Mouton.

Zhabotynska, S.A. (2010). Principles of building conceptual models for thesaurus dictionaries. Cognition, communication, discourse. International On-line journal, 1, 75-92. Retrieved from http://sites.google.com/site/cognitiondiscourse/vypusk-no1-2010

References of illustrative material:

The Economist. (1929, 16 Nov). Retrieved from: http://gale.cengage.co.uk

The Economist. (2008, 19 March). Retrieved from: http://www.economist.com

The Economist. (1929, 26 Oct). Retrieved from: http://gale.cengage.co.uk 
The Economist. (2008, 7 Aug). Retrieved from: http://www.economist.com The Financial Times. (1932, 12 Feb). Retrieved from: http://gale.cengage.co.uk The Financial Times. (1930, 13 Dec). Retrieved from: http://gale.cengage.co.uk The Financial Times. (2008, 17 Sep). Retrieved from: http://www.ft.com The Financial Times. (2008, 18 Dec). Retrieved from: http://www.ft.com The Financial Times. (1929, 29 Oct). Retrieved from: http://gale.cengage.co.uk The Financial Times. (1932, 18 March). Retrieved from: http://gale.cengage.co.uk The Financial Times. (1931, 7 Jan). Retrieved from: http://gale.cengage.co.uk The New York Times. (2008, 1 Aug). Retrieved from: http://www.nytimes.com The New York Times. (2009, 12 Sep). Retrieved from: http://www.nytimes.com The New York Times. (2008, 8 Oct). Retrieved from: http://www.nytimes.com 